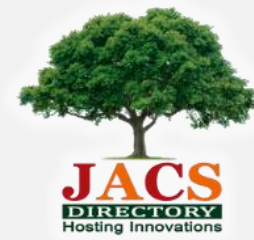

Journal of Nanoscience and Technology

\title{
Biosynthesis and Characterization of Silver Nanoparticles from Marine Macroscopic Red Seaweed Halymenia porphyroides Boergesen (Crypton)
}

\author{
M. Vishnu Kiran*, S. Murugesan \\ Unit of Algal Biotechnology and Bionanotechnology, PG and Research Department of Plant biology and Biotechnology, Pachaiyappa's College, University of \\ Madras, Chennai - 600 030, Tamilnadu, India.
}

\section{A R T I C L E DET A I L S}

\section{Article history:}

Received 26 March 2020

Accepted 21 April 2020

Available online 02 May 2020

\section{Keywords:}

Silver Nanoparticles

Biological Synthesis

Spectral Characterization

\begin{abstract}
A B S T R A C T
In the present study, economically scalable and energy efficient colloidal silver (Ag) nanoparticles were biosynthesized from marine red seaweed Halymenia porphyroides Boergesen (crypton) collected from southeast coast of Tamilnadu, India. The silver nanoparticles were biosynthesized as per green synthesis protocol. The rich presence of phytochemicals, bioactive compounds and secondary metabolites in marine macroscopic red seaweed Halymenia porphyroides Boergesen (crypton) play a major role since they possess reducing and capping agents for the biosynthesis of silver nanoparticles that may be environmentally acceptable and eco-friendly. Therefore, the red seaweed Halymenia porphyroides Boergesen was used in the experimental study for the biosynthesis of silver nanoparticle. The biosynthesized silver nanoparticles from marine macroscopic red seaweed Halymenia porphyroides Boergesen were characterized by UV-vis spectroscopy which confirmed the surface plasmon resonance of silver nanoparticles, Fourier transform infrared (FT-IR) spectroscopy to identify the presence of various functional groups in biomolecules responsible for the bio reduction of $\mathrm{Ag}^{+}$and capping/stabilization of silver nanoparticles. X-ray diffraction (XRD) to observe face center cubic (fcc) and crystalline nature of silver nanoparticles, thermo gravimetic analysis (TGA) which revealed the thermal stability and purity of the silver nanoparticles. Particle size distribution and morphology were investigated by scanning electron microscope (SEM) which showed silver nanoparticles in the size range of 34.3-80.5 nm. The particle distribution under different nanometers was analyzed using transmission electron microscopy (TEM).
\end{abstract}

\section{Introduction}

Nanoscience and nanotechnology are the study and application of extremely small things and can be used across all the other science fields, such as chemistry, biology, physics, materials science, and engineering. Nanomaterials and nanoparticles are emerging as increasing scientific research due to their potential for achieving specific processes and selectivity, especially in biological and pharmaceutical industries [1-7]. The use of biological entities for the biosynthesis of nanoparticles has been of great interest in the past few decades due to their unusual optical [8], chemical [9], photo electrochemical [10] and electronic properties [11]. The size and shape of nanomaterials strongly influences their electromagnetic, optical and catalytic properties [12, 13]. The bacteria, fungi and seaweeds are used for the synthesis and assembly of nanoparticles which would result and benefit for the development of clean, nontoxic and environmentally acceptable "green chemistry" protocols $[14,15]$. One of the promising nanoparticles in nanotechnology is the nano silver due to its potential to exhibit as strong antimicrobial, antiviral, superior catalytic activity and enhanced surface Raman spectroscopy [16-18].

Silver nitrate was used to treat ulcers during $17^{\text {th }}$ and $18^{\text {th }}$ century, whereas in $19^{\text {th }}$ century silver nitrate pencils formed part of the standard surgical equipment [19]. Silver and its compounds are used as a biocide in the prevention of infections in burns, traumatic wounds and diabetic ulcers [20]. The reemergence and the use of silver have been used as a viable treatment for infections encountered in burns due to the stimulus publication by Moyer et al [21-24]. The other uses of silver would include as disinfectant in water treatment and as a coating in catheters as well as other medical devices implanted on/within the body [25, 26]. Silver nanoparticles remains to be one of the important scientific researches over past few decades and find their applications in the field of life sciences

especially in food chemistry [27], biomedicine [28], and agriculture [29]. Silver based nanoparticles have been synthesized by various synthetic methods involving physical, chemical [30] and biochemical techniques [31]. Currently with the increase on the focus of green chemistry the nanoparticles like silver, gold and CdS have been synthesized by biological methods using microorganisms [32-34], enzymes [35] and seaweeds or plant extracts [36-38]. Biomolecules have been used for nanomaterial synthesis/functionalization and in subsequent applications for decades [39]. The literature survey revealed that the nanoparticle synthesis using biological sources like plants/seaweeds has been unexplored and unexploited [40-43]. In the present study the green synthesis of silver nanoparticles from marine macroscopic red seaweed Halymenia porphyroides Boergesen (crypton) was biosynthesized and their characterization was studied by using UV-vis spectroscopy, Fourier transform infrared (FT-IR) spectroscopy, X-ray diffraction (XRD), Thermo gravimetic analysis, scanning electron microscope (SEM) and transmission electron microscopy (TEM).

\section{Experimental Methods}

\subsection{Collection and Preparation of Seaweed Extract}

The marine red seaweed Halymenia porphyroides Boergesen (Crypton) was collected on summer season from 2.5-meter rapid intertidal regions of the Gulf of Mannar-Mandapam (latitude $9^{\circ} 17^{\prime \prime} \mathrm{N}$, longitude $79^{\circ} 11^{\prime \prime} \mathrm{E}$ ), Ramanathapuram District, South East Coast of Tamilnadu, South India. Collected seaweed was washed with sea water for eliminating impurities such as sand, rocks, epiphytes and epifauna. The washed samples were preserved with $5-10 \%$ formaldehyde in sea water and transported to the laboratory in a box containing slush ice. The fumes of the formaldehyde would help to fix and preserve the seaweed material. In the laboratory, the samples were washed thoroughly in running tap water to remove salt and washed three times using distilled water which may remove metallic compounds and it was shade dried at room temperature $\left(37^{\circ} \mathrm{C}\right)$ for 10 
days. The dried seaweed materials were crushed by using mortar and pestle to get the powder form and it was stored in an air-tight container. About $1 \mathrm{~g}$ of crushed seaweed powder was added with $100 \mathrm{~mL}$ of distilled water in $250 \mathrm{~mL}$ conical flask and boiled for $5-10$ minutes at $60-80^{\circ} \mathrm{C}$. The crude extract was then collected and stored at $4{ }^{\circ} \mathrm{C}$ for experimental use [44].

\subsection{Biosynthesis of Silver Nanoparticles}

The crude extract of the experimental marine red seaweed Halymenia porphyroides was used for the biosynthesis of silver nanoparticles. Silver nitrate $\left(\mathrm{AgNO}_{3}\right.$-) (SD fine) was used for the synthesis of silver nanoparticles and double-distilled, deionized water was used for all the experiments. The silver nanoparticle formation was carried out by taking $500 \mathrm{mg}$ of dry, shade dried powder samples of the seaweed Halymenia porphyroides in a $250 \mathrm{~mL}$ Erlenmeyer flask with $10^{-3} \mathrm{M}$ aqueous $\mathrm{AgNO}_{3-}$ solution and was incubated at room temperature. The $\mathrm{pH}$ was checked during the course of reaction and it was found to be 5.09 . Nearly $95 \%$ of bio reduction of $\mathrm{AgNO}_{3}$ - ions occurred within $24 \mathrm{hr}$ at stirring condition. The biosynthesis of silver nanoparticles was characterized by UV Vis spectroscopy; size and morphology by employing SEM and TEM, structure from X-ray diffraction (XRD) technique, stability and purity of silver nanoparticles from Thermo gravimetric analysis (TGA) and biomolecules involved in the capping agent of silver nanoparticles from Fourier transform infrared (FT-IR) spectroscopy.

\section{Result and Discussion}

\subsection{Visual Examination}

The biosynthesis of silver nanoparticles was primarily identified by color change during exposure of crude seaweed extract of the Halymenia porphyroides into aqueous solution of silver ions is shown in Fig. 1. The shade dried powder preparations of the experimental seaweed Halymenia porphyroides were added in $10^{-3} \mathrm{M}$ silver nitrate solution and allowed to react at $121^{\circ} \mathrm{C}$ for 20 minutes. The colour of the reaction solution changed to dark reddish. The control (without seaweed powder) showed no colour formation. Formation of the colour arises due to the excitation of surface plasmon vibrations where the metabolites in the seaweed extract act as the capping agent. The colour of the solution gradually intensified on heating which clearly indicates and confirms the formation of silver nanoparticles. After $24 \mathrm{hr}$, there is no significant color change, indicating the saturation of the reaction of silver nanoparticle formation.

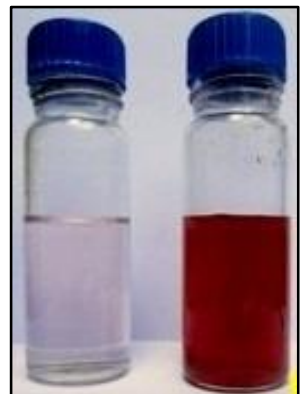

Fig. 1 Aqueous extract of Halymenia porphyroides before and after synthesis of silver nanoparticles

\subsection{UV-Visible Spectroscopic Analysis}

The silver nanoparticles synthesized by marine red seaweed Halymenia porphyroides were analyzed by using UV-Vis spectrophotometer (Labtron LUS-B16). The absorption spectra of silver nanoparticles formed in the reaction solution were characteristic of the nanoparticle from the seaweed and had specific absorption maxima at $430.5 \mathrm{~nm}$ is shown in Fig. 2. The characteristic absorption peaks of the silver nanoparticles are in the range between 410 to $440 \mathrm{~nm}$, which confirms the synthesis and formation of silver nanoparticles $[45,46]$. The frequency and width of the surface plasmon absorption depend on the size and shape of the metal nanoparticles as well as on the dielectric constant of the metal itself and the surrounding medium [47]. The broad peaks of the absorption spectra indicate the presence of biosynthesized silver nanoparticles from the experimental seaweed Halymenia porphyroides with large size distribution and are polydispersed. The interaction with the biomolecules presents in the aqueous part of the reaction solution by the biosynthesized silver nanoparticles from experimental seaweed Halymenia porphyroides has been indicated by UV Visible spectroscopic analysis. There were no little signs of aggregation with the biosynthesized silver nanoparticles solution which were stable for more than six months of observation. https://doi.org/10.30799/jnst.298.20060202

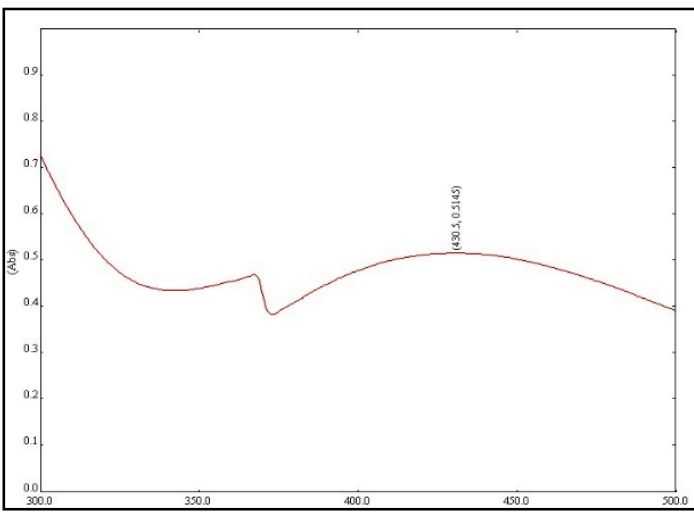

Fig. 2 UV Visible Spectral analysis of silver nanoparticles biosynthesized from Halymenia porphyroides

\subsection{FT-IR Spectroscopic Analysis (FTIR)}

The FTIR spectral measurements were carried out to identify the potential biomolecules in the crude extract of the seaweed Halymenia porphyroides which is responsible for reducing and capping the biologically reduced silver nanoparticles. Silver nanoparticles biosynthesized from experimental seaweed Halymenia porphyroides were analyzed using FT-IR spectroscopy is shown in Fig. 3 and Table 1.

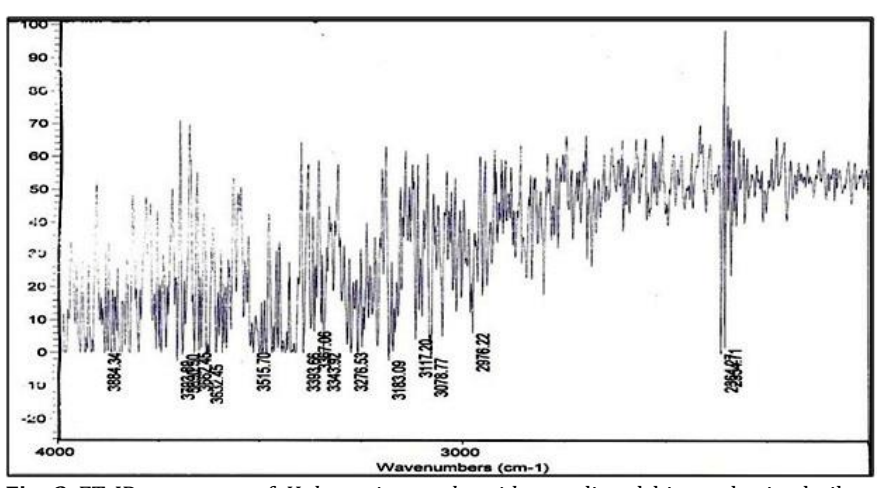

Fig. 3 FT-IR spectrum of Halymenia porphyroides mediated biosynthesized silver nanoparticles

Table 1 FT-IR Spectral interpretation of silver nanoparticles biosynthesized from Halymenia porphyroides

\begin{tabular}{ll}
\hline Wave number $\left(\mathrm{cm}^{-1}\right)$ & Peak Assignments \\
\hline 3884.34 & O-H stretch free, alcohols \\
3703.80 & O-H stretch free, alcohols \\
3690.50 & O-H stretch free, alcohols \\
3662.45 & O-H stretch free, alcohols \\
3632.45 & O-H stretch free, hydroxyl, alcohols, phenols \\
3515.70 & O-H stretch, H-bonded alcohol, phenols \\
3393.66 & O-H stretch, H-bonded, alcohols, phenols \\
3367.06 & O-H stretch, H-bonded, alcohols, phenols \\
3343.92 & O-H stretch, H-bonded, alcohols, phenols \\
3276.53 & N-H, H-bonded stretch, $1^{\circ}, 2^{\circ}$ amines, amides \\
3183.09 & O-H stretch, carboxylic acids \\
3117.20 & O-H stretch, carboxylic acids \\
3078.77 & $=$ C-H stretch, alkanes \\
2976.22 & C-H stretch, alkanes \\
2354.71 & C=-N Stretch, nitrile
\end{tabular}

The local molecular environment of the organic molecules on the surface of the nanoparticles was determined by the IR spectra. Fourier transform infrared spectroscopy (FTIR) is a technique which is used to analyze the chemical composition of many organic chemicals, semiconductor materials, gases, biological samples, inorganics, and minerals. FTIR analysis can give not only qualitative (identification) analysis of materials, but, with relevant standards, can be used for quantitative (amount) analysis. The FT-IR spectrum analysis of silver nanoparticles biosynthesized from red seaweed manifests an absorption peak at $3884.34 \mathrm{~cm}^{-1}\left(\mathrm{O}-\mathrm{H}\right.$ stretch free, alcohols), $3703.80 \mathrm{~cm}^{-1}(\mathrm{O}-\mathrm{H}$ stretch free, alcohols), $3690.50 \mathrm{~cm}^{-1}$ (O-H stretch free, alcohols), 3662.45 $\mathrm{cm}^{-1}$ (O-H stretch free, alcohols), $3632.45 \mathrm{~cm}^{-1}$ (O-H stretch free, hydroxyl, alcohols, phenols), $3515.70 \mathrm{~cm}^{-1}$ (O-H stretch, H-bonded alcohol, phenols), $3393.66 \mathrm{~cm}^{-1}(\mathrm{O}-\mathrm{H}$ stretch, $\mathrm{H}$-bonded, alcohols, phenols), $3367.06 \mathrm{~cm}^{-1}$ (O-H stretch, $\mathrm{H}$-bonded, alcohols, phenols), $3343.92 \mathrm{~cm}^{-1}$ (O-H stretch, H-bonded, alcohols, phenols), $3276.53 \mathrm{~cm}^{-1}(\mathrm{~N}-\mathrm{H}, \mathrm{H}-$ bonded 
stretch, primary, secondary amines, amides), $3183.09 \mathrm{~cm}^{-1}(\mathrm{O}-\mathrm{H}$ stretch, carboxylic acids), $3117.20 \mathrm{~cm}^{-1}$ (O-H stretch, carboxylic acids), 3078.77 $\mathrm{cm}^{-1}$ (=C-H stretch, alkanes), $2976.22 \mathrm{~cm}^{-1}$ (C-H stretch, alkanes) [48] and $2354.71 \mathrm{~cm}^{-1}$ (C=N stretch, nitrile) [49]. The results revealed that the capping ligand of the silver nanoparticles may be an aromatic compound or alkanes or amines [50]. The biological molecules such as secondary metabolites could possibly play a major role in the synthesis and stabilization of the metal nanoparticles [51,52]. The Van-der-Waals forces between nitrogen and oxygen atoms as well as the release of protein molecules in bio compound of the experimental seaweed Halymenia porphyroides may be responsible for the biosynthesis and stabilization of silver nanoparticles in an aqueous solution. These results obtained are in good agreement with the literatures $[53,54]$.

\subsection{X-Ray Diffraction Pattern (XRD)}

$\mathrm{XRD}$ is a widely used to determine the size and crystal structure of silver nanoparticles. X-ray diffractogram of the biosynthesized silver nanoparticles by the experimental seaweed Halymenia porphyroides exhibits Bragg reflection corresponding to face centered cubic (fcc) type bulk silver. The broadened diffraction peaks around their base indicates that the silver nanoparticles are between nano sizes. XRD (Labtron LXRDA10) analysis of biosynthesized silver nanoparticles from Halymenia porphyroides exhibited four distinct diffraction peaks is shown in Fig. 4. The XRD diffraction pattern of biosynthesized silver nanoparticles from Halymenia porphyroides showed four distinct diffraction peaks at $12.13^{\circ}$, $28.77^{\circ}, 39.87^{\circ}$ and $46.11^{\circ}$ with $2 \theta$ values corresponding to the lattice

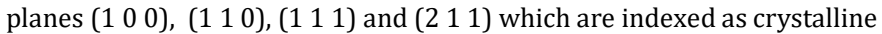
silver face-centered cubic (fcc) phase [55]. The observed peak broadening and noise was probably related to the effect of nano sized particles and the presence of various crystalline biological macromolecules in the experimental seaweed extract. The results are in agreement with the findings of earlier investigations as reported by Paneerselvam et al. [56] and Alak and Swapan, [57]. The diffraction patterns of silver nanoparticles biosynthesized from the experimental seaweed Halymenia porphyroides indicate the uniqueness of the crystalline structure, phase purity, degree of crystallinity and the unit cell parameters. The presence of some unassigned peaks in the X-ray diffractogram of the biosynthesized silver nanoparticles from the experimental seaweed Halymenia porphyroides may be due to the biomolecules and proteins in the seaweed extract which acts as stabilizing agents [58]. The XRD pattern thus clearly shows that the silver nanoparticles are crystalline in nature.

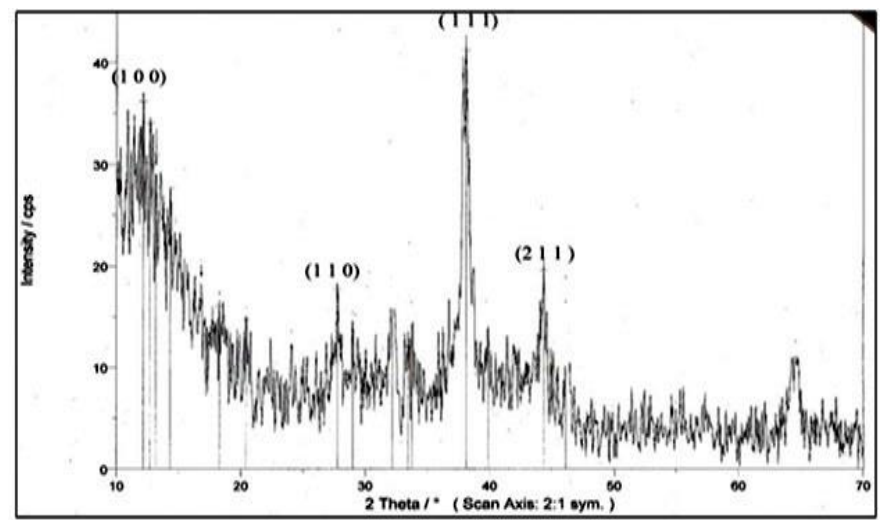

Fig. 4 X-ray diffraction analysis of sliver nanoparticles biosynthesized from Halymenia porphyroides

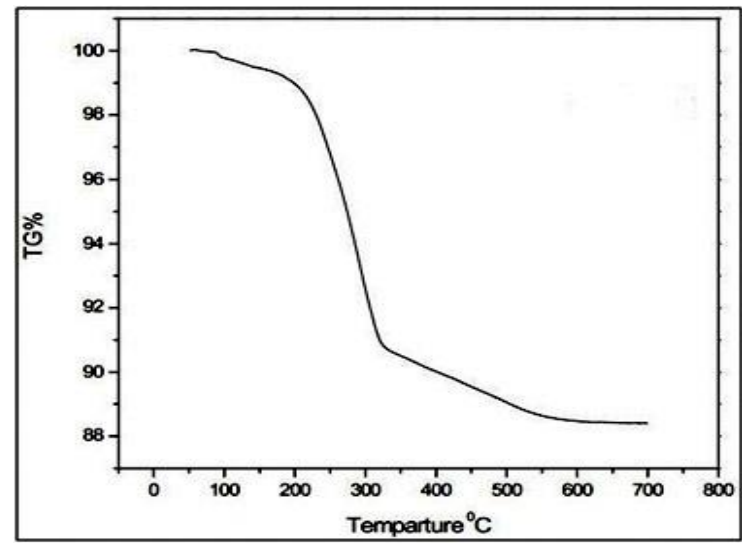

Fig. 5 TGA thermogram of silver nanoparticles biosynthesized from Halymenia porphyroides

https://doi.org/10.30799/jnst.298.20060202

\subsection{Thermo Gravimetric Analysis (TGA)}

The biosynthesized silver nanoparticles from the experimental seaweed Halymenia porphyroides were subjected to thermo gravimetric analysis (TGA 4000 - PerkinElmer) is shown in Fig. 5. The thermal stability, purity and humidity of the particles were determined using thermo gravimetric analysis [59]. The TGA relies on a high degree precision in three measurements: weight, temperature and temperature change. It can be applied to silver nanoparticles to determine changes in weight in relation to the changes in temperature [60]. Thermo gravimetric analysis is commonly employed in research and testing to determine the characteristics of materials such as degradation temperature, absorbed moisture content of nanoparticles and polymers [61]. The silver nanoparticles biosynthesized from Halymenia porphyroides showed a weight loss in a two-step process, the first step indicated a weight loss of $9 \%$ at the temperature up to $340{ }^{\circ} \mathrm{C}$ which corresponds to the decomposition of bioorganic compounds present in the nano particle powder [62] and the second step involved weight loss of $3 \%$ at the temperature ranging from $340-650{ }^{\circ} \mathrm{C}$ which corresponds to the decomposition of amines [63]. Thermal decomposition of the $\mathrm{Ag}^{+}$ bioorganic complex at high temperature $\left(200^{\circ} \mathrm{C}\right)$ results in an $\mathrm{Ag}$ atom and organic molecules [64]. The crystallite growth of silver nanoparticles biosynthesized from the experimental seaweed Halymenia porphyroides appears to be consistent with "Ostwald ripening" where the stability gradient diffuses from the surfaces of small particles to the surfaces of larger particles in the $\mathrm{Ag}^{+}$-bioorganic solution [65]. The TGA results of the biosynthesized silver nanoparticles, from experimental seaweed Halymenia porphyroides, show $95 \%$ purity and their stabilization were observed at $200{ }^{\circ} \mathrm{C}$ which are in agreement with the findings of the earlier investigations reported by Forough and Farhadi [66] and Amjad et al. [67] The $95 \%$ purity of the silver colloidal medium from the experimental seaweed Halymenia porphyroides was determined by an ultra-sonication method which eliminates and separates silver nanoparticles from bio organic complexes [68].

\subsection{Scanning Electron Microscopy (SEM)}

The morphology and shape of these silver nanoparticles were carried out using scanning electron microscopy (SEM Quanta - 400) shown in Fig. 6. The silver nanoparticles biosynthesized from Halymenia porphyroides biomass after exposure to $10^{-3} \mathrm{M}$ aqueous silver nitrate solution for 2 hours showed the colloidal form of the particles in solution which micro precipitated on the surface of the biomass of the experimental seaweed.

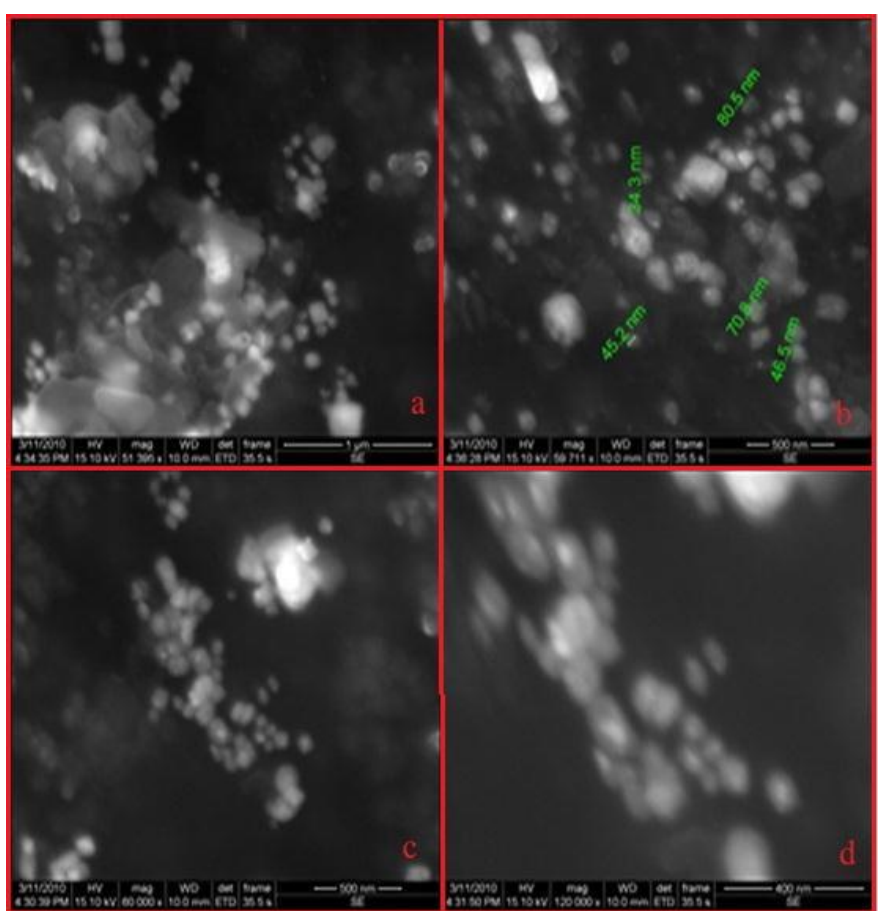

Fig. 6 Scanning electron micrograph of silver nanoparticles biosynthesized from Halymenia porphyroides

In the present study, the SEM analysis of silver nanoparticles, besides being present in colloidal form in solution was also micro precipitated on the surface of the biomass were clearly indicating that the nanoparticles formed by the reduction of $\mathrm{Ag}^{+}$ions are bound to the surface of the cells. The silver nanoparticles biosynthesized from Halymenia porphyroides formed were predominate in cubical and spherical structures with 
uniform shape as reported by Chandran et al. [69]. The brighter cubical and spherical area of the back scattered electron image corresponds to the silver nano particle indicating the cubic and spherical structure of silver. It is known that the shape of the metal nanoparticles has considerable changes their optical and electronic properties [70]. SEM pictures of silver nanoparticles from the experimental seaweed Halymenia porphyroides showed that they were intact after the reaction and immobilization. The experimental results showed that the diameter of prepared silver nanoparticles in the solution was about 34.3-80.5 $\mathrm{nm}$ for Halymenia porphyroides. Silver nanoparticles have a strong tendency to agglomerate which reduces the surface to volume ratio and thereby produce the catalytic effect. Therefore, a stabilizing agent is often used to prevent agglomeration. However, the agent is adsorbed on the surface of the nanoparticles, shielding them from the oxidant and reluctant and thereby inhibiting the catalysis [71].

\subsection{Transmission Electron Microscopy (TEM)}

The transmission electron microscopy (HR-TEM) is the technique used to determine the size and particle distribution of silver nanoparticles [72]. The size and distribution of biosynthesized silver nanoparticles were observed by taking the micrograph from drop coated films from silver complex solution with the extract of the experimental seaweed Halymenia porphyroides. The TEM (HR-TEM JEOL 3010) images showed the formation of spherical shaped silver nanoparticles and are found in aggregates ranging from 5 to $50 \mathrm{~nm}$ shown in Fig. 7.

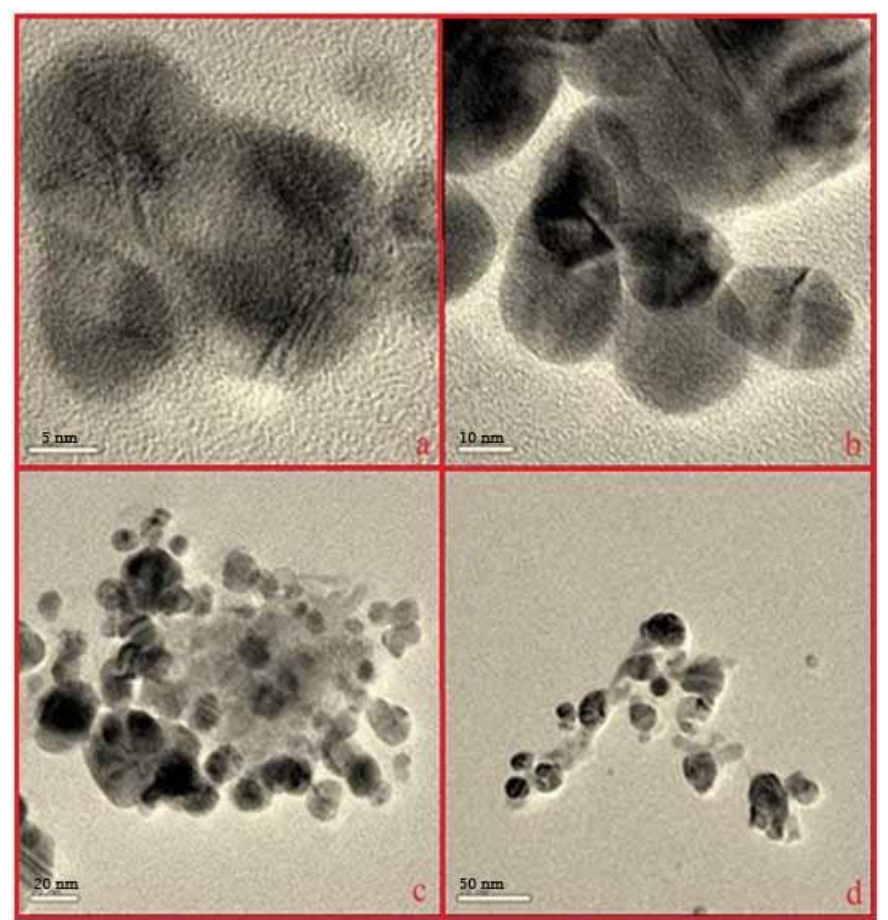

Fig. 7 HR-TEM images of silver nanoparticles biosynthesized from Halymenia porphyroides

The average mean size of silver nanoparticles from Halymenia porphyroides was $32 \mathrm{~nm}$. Similar results were recorded by Murugesan et al. [73] using red alga Gracilaria edulis extract as a reducing and capping agent. The shape of the metal nanoparticles has considerably changed their optical and electronic properties [74]. The HR-TEM images do not confirm the presence of capping agents on the silver nanoparticles, but under careful observation, it is noted that the silver nanoparticles are surrounded by a faint thin layer of other material, which may be the capping organic material from the experimental seaweed Halymenia porphyroides. The silver nanoparticles of the TEM images are not in physical contact but are separated from each other by a uniform inter particle distance. The results of HR-TEM findings indicate that the seaweed mediated silver nano particle shape varies as cubical and spherical which are in agreement with earlier investigations reported by Raghunandan et al. [75] and Noruzi et al. [76].

\section{Conclusion}

In the current study silver nanoparticles were synthesized thorough the biological medium by the reduction of silver nitrate using the crude extract of marine red seaweed Halymenia porphyroides. The reaction mixture was https://doi.org/10.30799/jnst.298.20060202 successfully optimized to increase the yield of silver nanoparticles production using UV-Vis analysis results. The optimum conditions were as follows: $500 \mathrm{~g}$ extract concentration, $10^{-3} \mathrm{M}$ aqueous $\mathrm{AgNO}_{3}$ - solution, 37 ${ }^{\circ} \mathrm{C}$ and $\mathrm{pH}$ 5.09. The Halymenia porphyroides seaweed extract acts as both reducing and stabilizing agents for the synthesis of silver nanoparticles, which were confirmed by FTIR. SEM analysis revealed that the silver nanoparticles ranged between $34.3 \mathrm{~nm}$ to $80.5 \mathrm{~nm}$ in size and were spherical with uniform distribution. TEM analysis revealed nearly spherical and hexagonal structures of the silver nanoparticles. The XRD pattern of silver nanoparticles showed a face-centred-cubic crystal structure. The purity and thermal stability of silver nanoparticles were detected by TGA analysis, which was closely related to that of bulk metallic silver, which indicates its purity and the thermal stability of the silver nanoparticle. The green protocol method used for the biosynthesis of silver nanoparticles using crude seaweed extract of Halymenia porphyroides makes the synthesis process energy efficient, economically scalable a well as non-toxic for its applications in food, pharmaceutical and nutraceutical industries. The seaweed extract contains bioactive compounds, secondary metabolites which act as strong capping and reducing agents in the synthesis process where $95 \%$ of the bio reduction of silver nanoparticles was observed. Thus, the seaweed extract makes an ideal source for the biosynthesis of silver nanoparticles for various applications such as drug delivery, catalytic activity, disinfectant, medicine and biomedical applications.

\section{Acknowledgement}

This work was carried out in part through the use of the Scanning Electron Microscopy (SEM) and Transmission Electron Microscopy (TEM) at Sophisticated Analysis Instrument Facility (SAIF), Indian Institute of Technology (IIT) - Madras, Tamilnadu, India. The Thermo gravimetric analysis (TGA) was carried out at Department of chemistry, Anna University, Chennai, Tamilnadu, India. The authors thank the above institutions for their instrumentation facility for the completion of the work.

\section{References}

[1] R. Feynman, There's plenty of room at the bottom, Science 254 (1991) 13001301.

[2] P. Alivisatos, The use of nanocrystals in biological detection, Nat. Biotechnol. 22 (2004) 47-52.

[3] J.C. Love, L.A. Estroff, J.K. Kriebel, R.G. Nuzzo, G.M. Whitesides, Self-assembled monolayers of thiolates on metals as a form of nanotechnology, Chem. Rev. 105 (2005) 1103-1169.

[4] C.A. Mirkin, T.A. Taton, Semiconductors meet biology, Nature 405 (2000) 626627.

[5] S. Nie, Y. Xing, G.J. Kim, J.W. Simons, Nanotechnology applications in cancer Annu. Rev. Biomed. Eng. 9 (2007) 257-288.

[6] M.D. Wang, D.M. Shin, J.W. Simons, S. Nie, Nanotechnology for targeted cancer therapy, Expert. Rev. Anticancer. Ther. 7 (2007) 833-837.

[7] M.C. Daniel, D. Astruc, Gold nanoparticles: assembly, supramolecular chemistry, quantum-size-related properties, and applications toward biology, catalysis, and nanotechnology, Chem. Rev. 104 (2004) 293-346.

[8] A. Krolikowska, A. Kudelski, A. Michota, J. Bukowska, SERS studies on the structure of thioglycolic acid monolayers on silver and gold, Surf. Sci. 532 (2003) 227-232.

[9] A. Kumar, S. Mandal, P.R. Selvakannan, R. Parischa, A.B. Mandale, M. Sastry, Investigation into the interaction between surface-bound alkylamines and gold nanoparticles, Langmuir. 19 (2003) 6277-6282.

[10] N. Chandrasekharan, P.V. Kamat, Improving the photoelectrochemical performance of nanostructured TiO2 films by adsorption of gold nanoparticles, J. Phys. Chem. B 104 (2000) 10851-10857.

[11] G. Peto, G.L. Molnar, Z. Paszti, O. Geszti, A. Beck, L. Guczi, Electronic structure of gold nanoparticles deposited on SiOx/Si, Mater. Sci. Eng. C 19 (2002) 95-99.

[12] C. Burda, X. Chen, R. Narayanan, M.A. El-Sayed, Chemistry and properties of nanocrystals of different shapes, Chem. Rev. 105 (2005) 1025-1102.

[13] P. Mulvaney, Surface plasmon spectroscopy of nanosized metal particles, Langmuir 12 (1996) 788-798.

[14] D. Bhattacharya, G. Rajinder, Nanotechnology and potential of microorganisms Crit. Rev. Biotechnol. 25 (2005) 199- 204.

[15] M. Sastry, A. Ahmad, M.I. Khan, R. Kumar, Microbial nanoparticle production. In: Niemeyer CM, Mirkin CA (eds)., Nanobiotechnology, Wiley-VCH, Weinheim, Germany, 2004, pp.126-135.

[16] F. Furno, K.S. Morley, B. Wong, B.L. Sharp, P.L. Arnold, et al., Silver nanoparticles and polymeric medical devices: A new approach to prevention of infection, J. Antimicrobial Chemother. 54(6) (2004) 1019-1024.

[17] C.F. Mao, M.A. Vannice, Formaldehyde oxidation over Ag catalysts, J. Catal. 154 (1995) 230-244.

[18] J. Hu, B. Zhao, W. Xu, B. Li, Y. Fan, Surface enhanced Raman spectroscopy study on the structure changes of 4-ercaptopyridine adsorbed on silver substrates and silver colloids, Spectrochim. Acta. A 58 (2002) 2827-2834.

[19] H.J. Klasen, Historical review of the use of silver in the treatment of burns, I. Early uses, Burns. 26 (2000) 117-130. 
[20] S. Silver, L.T. Phung, G. Silver, Silver as biocides in burn and wound dressings and bacterial resistance to silver compounds, J. Ind. Microbiol. Biotechnol. 33(7) (2006) 627-634.

[21] C.A. Moyer, A treatment of burns, Trans. Stud. Coll. Physicians. Philadelphia 33 (1965) 53-103.

[22] C.A. Moyer, Some effects of 0.5 per cent silver nitrate and high humidity upon the illness associated with large burns, J. Natl. Med. Assoc. 57 (1965) 95-100.

[23] C.A. Moyer, L. Brentano, D.L. Gravens, H.W. Margraf, W.W. Monafo Jr, Treatment of large human burns with 0.5 per cent silver nitrate solution, Arch. Surg. 90 (1965) 812-867.

[24] H.J. Klasen, A historical review of the use of silver in the treatment of burns, II. Renewed interest for silver, Burns. 26 (2000) 131-138.

[25] B.S. Atiyeh, M. Costagliola, S.N. Hayek, S.A. Dibo, Effect of silver on burn wound infection control and healing: review of the literature, Burns. 33 (2007) 139148.

[26] R.O. Darouiche, Anti-infective efficacy of silver-coated medical prostheses, Clin. Infect. Dis. 29 (1999) 1371-1377.

[27] H. Li, F. Li, L. Wang, J. Shengv, Z. Xin, L. Zhao, Effect of nanopacking on preservation quality of Chinese jujube (Ziziphus jujube Mill. Var. inermis (Bunge) Rehd), Food. Chem. 114 (2009) 547-552.

[28] K. Chaloupka, Y. Malam, A.M. Seifalian, Nanosilver as a new generation of nanoproduct in biomedical applications, Trends. Biotechnol. 28 (2010) 580588.

[29] H.J. Park, H.K. Sung H.J. Kim, S.H.A. Choi, A new composition of nanosized silicasilver for control of various plant diseases, J. Plant. Pathol. 22 (2006) 295-302.

[30] S. Sinha, I. Pan, P. Chanda, S.K. Sen, Nanoparticle's fabrication using ambient biological resources, J. Appl. Biosci. 19 (2009) 1113-1130.

[31] J. Huang, Q. Li, D. Sun, Y. Lu, Y. Su, et al., Biosynthesis of silver and gold nano particles by novel sundried Cinnamomum camphora leaf, Nanotechnol. 18 (2007) 105104-105114.

[32] T. Klaus, R. Joerger, E. Olsson, C.G. Granqvist, Silver-based crystalline nanoparticles, microbially fabricated, Proc. Natl. Acad. Sci. USA 96 (1999) 13611-13614.

[33] Y. Konishi, K. Ohno, N. Saitoh, T. Nomura, S. Nagamine, et al., Bioreductive deposition of platinum nanoparticles on the bacterium Shewanella algae, J. Biotechnol. 128 (2007) 648-653.

[34] B. Nair, T. Pradeep, Coalescense of nanoclusters and formation of submicron crystallites assisted by Lactobacillus strains, Cryst. Growth. Des. 2(4) (2002) 293-298.

[35] I. Willner, R. Baron, B. Willner, Growing metal nanoparticles by enzymes, Adv. Mater. 18 (2006) 1109-1120.

[36] S.S. Shankar, A. Rai, A. Ahmad, M. Sastry, Rapid synthesis of Au, Ag, and bimetallic Au core Ag shell nanoparticles using Neem (Azadirachta indica) leaf broth, J. Colloid. Interface. Sci. 275 (2004) 496-502.

[37] M. Vishnu Kiran, S. Murugesan, Biogenic silver nanoparticles by Halymenia poryphyroides and its in vitro anti-diabetic efficacy, J. Chem. Pharm. Res. 5 (12) (2013) 1001-1008.

[38] M. Vishnu Kiran, S. Murugesan, Biosynthesis of silver nanoparticles from marine alga Colpomenia sinuosa and its antibacterial efficacy, Int. J. Curr. Microbiol. App. Sci. 3(4) (2014) 1-7.

[39] C.M. Niemeyer, Nanoparticles, Proteins, and nucleic acids: biotechnology meets materials science, Angew. Chem. Int. Ed. 40 (2001) 4128-4158.

[40] P. Rajasulochana, R. Dhamotharan, P. Murugakoothan, S. Murugesan, P. Krishnamoorthy, Biosynthesis and characterization of gold nanoparticles using the alga Kappaphycus alvarezii, Int. J. Nanosci. 9(5) (2010) 511-519.

[41] S. Swaminathan, S. Murugesan, S. Damodarkumar, R. Dhamotharan, S. Bhuvaneswari, Synthesis and characterization of gold nano particles from alga Acanthophora specifera (VAHL) Boergesen, Intl. J. Nanosci. Nanotech. 2(2) (2011) 85-94.

[42] R. Dhamotharan, D. Punitha, S. Murugesan, T.S. Subha, Brown algal biomass mediated biosynthesis of gold nanoparticles, Intl. J. Nanosci. Nanotech. 1(1) (2010) 37-44.

[43] D. Radhika, C. Veerabahu, L. Sakthibama, S. Murugesan, Green synthesis of gold nanoparticles by the marine alga Stoechospermum marginatum, Intl. J. Nanotech. Appl. 6(1) (2012) 61-70.

[44] K.S. Rajesh, C. Malrakodi, K.S. Venkat, Synthesis and characterization of silver nanoparticles from marine brown seaweeds and its antifungal efficiency against clinical fungal pathogens, Asian. J. Pharm. Clin. Res. 10 (2017) 190-193.

[45] A. Henglein, Physicochemical properties of small metal properties in solution: "micrelectrode" reactions, chemisorption's, composite metal particles and the atom to metal transition, J. Phy. Chem. 97 (1993) 5457-5471.

[46] P. Kumar, S. Senthamilselvi, A. Lakshmi Prabha, K. Prem Kumar, R.S. Ganesh Kumar, M. Govindaraju, Synthesis of silver nano particles from Sargassum tenerrimum and screening phytochemicals on its antibacterial activity, Nano. Biomed. Engg. 4 (2012) 12-16.

[47] M. Sastry, V. Patil, S.R. Sainkar, Electrostatically controlled diffusion of carboxylic acid derivatized silver colloidal particles in thermally evaporated fatty amine films, J. Phy. Chem. B 102 (1998) 1404-1410.

[48] R.M. Silverstein, F.X. Webster, Spectrometric identification of organic compounds, John Wiley and Sons, Inc., New York, 1998.
[49] M.O. O'Coinceanainn, C. Astill, S. Schumm, Potentiometric FTIR and NMR studies of the complexation of metals with theaflavin, Dalton. Trans. 5 (2003) 801-807.

[50] Inbakandan, Venkatesan, A. Khan, Biosynthesis of gold nanoparticles utilizing marine sponge Acanthella elongata (Dendy, 1905), Colloids Surf. B: Biointerf. 81(2) (2010) 634-639.

[51] R. Sathyavathi, M. Balamurali Krishna, S.R. Venugopal Rao, R. Saritha, D. Narayana Rao, Biosynthesis of silver nano particles using Coriandrum sativum leaf extract and their application in nonlinear optics, Adv. Sci. Lett. 3(2) (2010) $1-6$.

[52] S. Rashmi, V. Preeti, P. Sadhna, Enzymatic formation of gold nanoparticles using Phanerochaete chrysosprium, Adv. Chem. Eng. Sci. 1(3) (2011) 154-162.

[53] Q. Chen, G. Liu, G. Chen, T. Mi, J. Tai, Green synthesis of silver nanoparticles with glucose for conductivity enhancement of conductive ink, Bioresources 12 (2016) 608-621.

[54] S. Zavoi, F. Fetea, F. Ranga, R. Pop, A. Baciu, C. Socaciu, Comparative fingerprint and extraction yield of medicinal herb phenolics with hepatoprotective potential, as determined by UV-Vis and FT-MIR spectroscopy, Not. Bot. Horti Agrobot. Cluj-Napoca. 39 (2011) 82-89.

[55] D.V. Leff, L. Brandt, J.R. Heath, Synthesis and characterization of hydrophobic organically soluble gold nanocrystals functionalized with primary amines, Langmuir 12 (1996) 4723-4730.

[56] C. Paneerselvam, S. Ponarulselvam, K. Murugan, K. Kalimuthu, S. Thangamani, Synthesis of silver nanoparticles using leaves of Catharanthus roseus Linn. G. Donn and their antiplasmodial activities, Asian. Pac. J. Trop. Biomed. 2(7) (2012) 574-580.

[57] D. Alak Chandra, S. Swapan Kumar, Mycogenic silver nanoparticle biosynthesis and its pesticide degradation potentials, Int. J. Tech. Enhanc. Emer. Eng. Res. 3(5) (2015) 108-113.

[58] P. Daizy, Biosynthesis of $\mathrm{Au}, \mathrm{Ag}$ and $\mathrm{Au}-\mathrm{Ag}$ nanoparticles using edible mushroom extract, Spectrochim. Acta A 73(2) (2009) 374-381.

[59] S.K. Bajpai, Y. Murali Mohan, Recent advances in nanoscience and technology, Bentham Science Publishers, Dubai, 2009.

[60] M.L. Assael, K. Gialou, Measurement of the thermal conductivity of stainless steel AISI 304 L up to 550 K, Int. J. Therm. Phy. 24(4) (2003) 1145-1153.

[61] A.N. Ananth, S. Umapathy, J. Sophia, T. Mathavan, D. Mangalaraj, On the optical and thermal properties of in situ/ex situ reduced Ag NP's/PVA composites and its role as a simple SPR-based protein sensor, App. Nanosci. 1(2) (2011) 8796.

[62] Z.H. Mbhele, M.G. Salemane, D.G.C.E. Van Sittert, J.M. Nedeljkovic, V. Djokovic A.S. Luyt, Fabrication and characterization of silver-polyvinyl alcohol nano composites, Chem. Mater. 15 (2003) 5019-5024.

[63] B. Xu, L. Qian, X. Liu, C. Song, Z. Yan, Synthesis and characterization of magnesium substituted aluminophosphate molecular sieves with AEL Structure, J. Nat. Gas. Chem. 13 (2004) 231-237.

[64] S. Yu-yuan, B. Sun, Z. Zhou, W. Yong-Tao, Z. Mei-Fang, Size-controlled and largescale synthesis of organic-soluble Ag nanocrystals in water and their formation mechanism, Prog. Nat. Sci.: Mat. Intl. 21(6) (2011) 447-454.

[65] A. Smith, Particle growth in suspensions, Academic Press, London, 1983.

[66] M. Forough, K. Farhadi, Biological and green synthesis of silver nanoparticles, Turkish J. Eng. Env. Sci. 34 (2010) 281-287.

[67] H. Amjad, K. Jamaroz, F.K Muhammad, Synthesis and characterization of antimicrobial polymer containing silver nano particles. Pakis. Oral Dent. J. 32(3) (2012) 539-539.

[68] P. Dhandapani, N. Supraja, Extracellular synthesis of silver nano particles by marine thermophilic bacteria, Intl. J. Pharm. Biol. Arch. 3(6) (2012) 14181423

[69] S.P. Chandran, M. Chaudhary, R. Pasricha, A. Ahmad, M. Sastry, Synthesis of gold and silver nano particles using aloe vera plant extract. J. Biotechnol. Prog. 22 (2006) 577-583.

[70] B.J. Crawford, R.D. Burke, Application of SEM and TEM techniques for Mgbased hydrogen storage, Cell. Biol. 74 (2004) 411-441.

[71] Z.J. Jiang, C.Y. Liu, L.W. Sun, Catalytic properties of silver nanoparticles supported on silica spheres, Am. Chem. Soc. 109(5) (2004) 4459-4463.

[72] A. Ahmad, P. Mukerjee, S. Senapati, D. Mandal, M.I. Khan, R. Kumar Extracellular biosynthesis of silver nano particles using the fungus Fusarium oxysporum, Colloid. Surf. B 28 (2003) 313-318.

[73] S. Murugesan, M. Elumalai, R. Dhamotharan, Green synthesis of silver nanoparticles from marine alga Gracilaria edulis S.G (Gmelin) P.C. Silva, Biosci. Biotech. Res. Comm. 4(1) (2011)105-110.

[74] A.N. Shipway, E. Katz, I. Willer, Nano particle arrays on surfaces for electronic optical and sensor applications, Chem. Phys. Chem. 1(1) (2000) 18-52.

[75] D. Raghunandan, S. Basavaraja, B. Mahesh, S. Balaji, S.Y. Manjunath, A Venkataraman, Biosynthesis of stable poly shaped gold nano particles from microwave- exposed aqueous extracellular anti-malignant guava (Psidium guajava) leaf extract, Nano. Biotechnol. 5(1-4) (2009) 34-41.

[76] M. Noruzi, D. Zare, K. Khoshnevisan, D. Davoodi, Rapid green synthesis of gold nano particles using Rosa hybrid petal extract at room temperature, Spectrochim. Acta A 79(5) (2011) 1461-1465. 